BJHS: Themes 2:101-125, 2017. C British Society for the History of Science 2017. This is an Open Access article, distributed under the terms of the Creative Commons Attribution-

NonCommercial-NoDerivatives licence (http://creativecommons.org/licenses/by-nc-nd/4.0/), which permits non-commercial re-use, distribution, and reproduction in any medium, provided the original work is unaltered and is properly cited. The written permission of Cambridge University Press must be obtained for commercial re-use or in order to create a derivative work.

doi:10.1017/bjt.2017.4 First published online 23 March 2017

\title{
Synthetic primatology: what humans and chimpanzees do in a Japanese laboratory and the African field
}

\author{
NICOLAS LANGLITZ*
}

\begin{abstract}
Against the background of humanities writing about animal agency, this article examines primatologist Tetsuro Matsuzawa's work with his 'research partner', the chimpanzee $\mathrm{Ai}$, and her conspecifics at the Kyoto University Primate Research Institute and in an outdoor laboratory in Guinea from 1976 to 2016. This latest chapter in the history of Japanese primatology describes an attempt at synthesizing benchwork and fieldwork. It examines how what both humans and chimpanzees can do varies across a whole spectrum of scientific practices, bridging the gap between controlled experiments and field observations. While some recent animal studies literature has presented laboratory animals as deprived of agency and thereby implicitly attributed agency to creatures of the wild, this historical and ethnographic account does not take the analytic category of agency for granted, but examines how Japanese primatologists think about the ways in which chimpanzees interact with each other, with humans and with their environment.
\end{abstract}

Ai probably spent the first months of her life in the wild of Guinea, until an animal dealer captured the chimpanzee infant and sold her to a cognitive-science laboratory in a small town in Japan. There, she worked her way up from subject of behaviourist conditioning to Tetsuro Matsuzawa's 'research partner' in a scientific endeavour named after her. ${ }^{1}$ Since 1976, the Ai Project has explored the chimpanzee mind, both in the lab and in the field. Based on historical inquiry and ethnographic fieldwork at Kyoto University Primate Research Institute (KUPRI) in Inuyama, as well as at Matsuzawa's outdoor laboratory in Bossou, Guinea, this article recounts one of the most recent chapters in

* Department of Anthropology, the New School for Social Research, New York, USA. Email: langlitn@ newschool.edu.

This research would not have been possible without the generous support of Tetsuro Matsuzawa and his colleagues at the Kyoto University Primate Research Institute, Japan, and in Bossou, Guinea. I am also grateful to Satoshi Hirata, Naruki Morimura and Mike Seres, who introduced me to their work at Kumamoto Sanctuary, and to Osamu Sakura and Cat Hobaiter, who provided very different angles on chimpanzee life and Japanese primatology. For comments on earlier drafts of this paper, I would like to thank Talia Dan-Cohen, Gabriela Bezerra de Melo Daly, Hugh Raffles, Tobias Rees, Wakana Suzuki and two anonymous peer reviewers. I also profited from the piercing critiques of the participants of the Berlin workshop Evidentiary Practices, especially Michael Guggenheim's.

1 Tetsuro Matsuzawa, 'The Ai Project: historical and ecological contexts', Animal Cognition (2003) 6, pp. 199-211, 199. 
the history of Japanese primatology. It has grown out of a tradition of humanities writing about primates and primatologists dating back to the 1980s, which emphasizes animal agency. In opposition to a view of animals as mindless automata, mere vehicles of selfish genes, driven by instincts, determined by their brains, constrained by local environments, selected for by nature, and conditioned by behaviourist psychologists, the proponents of animal agency extended to species other than Homo sapiens the privilege of acting in one way even though they could have acted differently. As a contribution to a special issue of BJHS Themes on animal agency, this article examines how the power of humans and chimpanzees to act otherwise varies across a whole spectrum of scientific practices, bridging the gap between controlled experiments and field observations, which constitute Matsuzawa's synthesis of primatological bench- and fieldwork. It also raises a critical question whether anthropologists and historians of science should speak of 'animal agency' in primatology.

\section{No agency in primatology?}

During eight months of fieldwork among primatologists nobody ever used the word 'agency'. I have searched the primatological literature for it and found nothing but acknowledgements of funding and government agencies. ${ }^{2}$ Even ape language researcher Sue Savage-Rumbaugh, celebrated by an animal studies scholar and ridiculed off the record by her fellow primatologists for crediting her bonobos as co-authors of a scientific journal article on animal welfare, has hardly ever spoken of 'agency'. ${ }^{3}$ The term's association with metaphysics of freedom barred it from primatology. The natural-scientific quest for a determinist account of the physical world was only undermined by the discovery of chance, not agency. ${ }^{4}$ Euro-American life sciences explain animal behaviour proximately in terms of genetic, neural, endocrinological, ecological or social determinants and ultimately through natural selection of random mutations. The anthropologist and historian of science Pamela Asquith pointed to the distinction between these technical languages of the behavioural sciences, which avoided the attribution of agency to animal actors, and ordinary-language terminology, which did exactly that. ${ }^{5}$ But talk about 'agency' as such is far from vernacular among English-speakers - it belongs to a metaphysical discourse characteristic of the humanities, including the Japanese humanities, which translate the English term as koui-syutai or koui-sha. Thus an anthropology and history of science focusing on animal agency in primatology introduces an etic concept that has had no place in the epistemic formations to be accounted for.

2 The exception that proves the rule is an article in a philosophy journal, co-authored by a primatologist: Caroline T. Arruda and Daniel J. Povinelli, 'Chimps as secret agents', Synthese (2016) 193, pp. 2129-2158.

3 Gay A. Bradshaw, 'An ape among many: animal co-authorship and trans-species epistemic authority', Configurations (2010) 18, pp. 15-30; Sue Savage-Rumbaugh, Kanzi Wamba, Panbanisha Wamba and Nyoto Wamba, 'Welfare of apes in captive environments: comments on, and by, a specific group of apes', Journal of Applied Animal Welfare Science (2007) 10, pp. 7-19.

4 Ian Hacking, The Taming of Chance, New York: Cambridge University Press, 1990.

5 Pamela J. Asquith, 'Of bonds and boundaries: what is the modern role of anthropomorphism in primatological studies?', American Journal of Primatology (2011) 73, pp. 238-244, 239. See also Eileen Crist, Images of Animals: Anthropocentrism and Animal Mind, Philadelphia: Temple University Press, 1999. 
It is hard to come by sources that would explain why the concept of agency did not catch on among primatologists, neither in Europe nor in America or Japan, while post-humanities scholars writing about animals quickly promoted the term to one of their key concepts. It helps to remember, though, that animal studies emerged from the humanities, which originally understood agency as the freedom from determination by external causes such as social structures and, in more demanding definitions, freedom from internal causes like genes or neural processes as well. This capacity for self-determination did not account for everything Homo sapiens did, but a dialectics of agency and determinism has driven the human sciences ever since their inception in nineteenth-century Europe. These disciplines have constantly oscillated between, on the one hand, a quest for universal laws structuring human action and, on the other, the celebration and occasionally bemoaning of individual and collective initiative, assigning humans a place at the helm of history. ${ }^{6}$ By contrast, no dialectic of agency and determinism has ever shaped the history of the natural sciences, which, at least as far as animal behaviour is concerned, have tended to subscribe to determinist metaphysics or the positivist shunning of all metaphysical speculation. ${ }^{7}$ Considering that most primatologists, including Matsuzawa, think of themselves as natural scientists, it cannot come as a surprise that they have not participated in discussions of animal agency.

In Japan, however, the situation is more complicated. Ever since Asquith submitted her widely received but never published doctoral thesis comparing anthropomorphism in Western and Japanese studies of the social behaviour of non-human primates, the expression 'Japanese primatology' has become almost synonymous with the Kyoto school, which Kinji Imanishi founded after the Second World War. ${ }^{8}$ Although trained as an entomologist, Imanishi began his academic career as a lecturer at the Institute for Humanistic Studies of Kyoto University, which, in 1959, promoted him to professor of social anthropology. ${ }^{9}$ He came to conceive of his so-called sociological approach to

6 Amanda Anderson and Joseph Valente, 'Introduction: discipline and freedom', in Joseph Anderson, Amanda Anderson and Joseph Valente (eds.), Disciplinarity at the Fin de Siècle, Princeton, NJ: Princeton University Press, 2002, pp. 1-18.

7 Of course, quantum physics introduced a non-determinist logic into the natural sciences, but it has not affected the behavioural sciences in any significant way other than inspiring speculations about whether quantum effects in the brain could serve as a basis for free will. But even the stochastic nature of quantum effects could hardly serve as a basis for animal agency, as post-humanists understand it.

8 Pamela J. Asquith, 'Some aspects of anthropomorphism in the terminology and philosophy underlying Western and Japanese studies of the social behaviour of non-human primates', D.Phil., University of Oxford, 1981, at http://ora.ox.ac.uk/objects/uuid:ced23a88-1ca0-47a9-a3be-a72dbaea1788; Asquith, 'Negotiating science: internationalization and Japanese primatology', in Shirley C. Strum and Linda M. Fedigan (eds.), Primate Encounters: Models of Science, Gender, and Society, Chicago: The University of Chicago Press, 2000, pp. 165-183; Asquith, 'Sources for Imanishi Kinji's views of sociality and evolutionary outcomes', Journal of Biosciences (2007) 32, pp. 635-641; Frans B.M. de Waal, 'Silent invasion: Imanishi's primatology and cultural bias in science', Animal Cognition (2003) 6, pp. 293-299; Donna J. Haraway, Primate Visions: Gender, Race, and Nature in the World of Modern Science, New York: Routledge, 1989, pp. 244-258; Hiroyuki Takasaki, 'Traditions of the Kyoto school of field primatology in Japan', in Strum and Fedigan, op. cit., pp. 151-164.

9 Pamela J. Asquith, 'Introduction', in Kinji Imanishi, A Japanese View of Nature: The World of Living Things (ed. Pamela J. Asquith), London: Routledge, 2002, pp. xxix-xliii, xxxi. 
non-human primates in particular and the world of living things in general as closer to the social sciences and the humanities than to the natural sciences. ${ }^{10}$

In 1948, Imanishi and his students inaugurated what came to be known as Japanese primatology as they set out to study Japanese macaques on the island of Koshima. Whereas the Osaka school sought inspiration from Harry Harlow's behavioural experiments, which they complemented with some fieldwork, and the medical school of the University of Tokyo conducted biomedical research on monkeys, Imanishi disdained 'people in white smocks' who 'have never once been out of the laboratory', where 'nature in its entirety, with flowers blooming, butterflies fluttering, and birds singing' could not be found. ${ }^{11}$ Instead he shaped the international perception of Japanese primatology as a radical field science, establishing a distinct style of naturalistic observation and anthropomorphic description, which set his school apart from the more natural-scienceoriented approaches favoured by his European and American colleagues. ${ }^{12}$ Imanishi and his students promoted a sociological and historical approach to primate societies, examining how monkey and ape societies emerged from contingent interactions between group members instead of assuming, as structural functionalists did, that a pre-existing social structure determined how individuals behaved. ${ }^{13}$

Imanishi also deviated from the intellectual project of Euro-American primatology in that he rejected Darwin's theorems of random variation and natural selection: the former condemned organisms to a 'completely blind existence'; the latter 'simply replaces human agency with nature'. ${ }^{14}$ Rather than imagining nature as an English pig breeder who singled out a few fortuitous mutants for reproduction, the Japanese scholar suggested that the ability of living things to control themselves and to respond to their environments was 'the same as humans' autonomy and independence'. ${ }^{15}$ Consequently, there was nothing inevitable or determinist about natural history. Imanishi emphasized the active role organisms took in their own evolution: 'Only when living things react, does the environment make them live. If organisms do not react, the environment presumably kills them and transforms them into matter. ${ }^{16}$ But note the dialectic quality of this interaction, which suggests that living things not only enjoy the same autonomy as humans, but also are subject to the same constraints. The opposing forces at work in the extension of the subject's autonomy over the environment and the simultaneous environmentalization of the subject left living things both free and not free, as

10 Kinji Imanishi, 'A proposal for shizengaku: the conclusion to my study of evolutionary theory', Journal of Social and Biological Structures (1984) 7, pp. 357-368.

11 Imanishi, op. cit. (10), pp. 357, 360.

12 Nobuyuki Kutsukake, 'Lost in translation: field primatology, culture, and interdisciplinary approaches', in Jeremy MacClancy and Agustín Fuentes (eds.), Centralizing Fieldwork: Critical Perspectives from Primatology, Biological and Social Anthropology, New York: Berghahn Books, 2011, pp. 104-120; Asquith, 'Negotiating science', op. cit. (8); Takasaki, op. cit. (8).

13 Michio Nakamura, 'Interaction studies in Japanese primatology: their scope, uniqueness, and the future', Primates (2009) 50, pp. 142-152.

14 Imanishi, op. cit. (9), pp. 73-74, 75.

15 Imanishi, op. cit. (9), pp. 30-31.

16 Imanishi, op. cit. (9), p. 74. 
Imanishi put it. ${ }^{17}$ As far as this iridescent ontology denied living things the autonomy it had just granted them, it took its cues from Imanishi's friend Kitaro Nishida, the founder of the Kyoto school of philosophy, who sought to conceptualize a form of self-determination without anything that did the determining. Nishida considered the obsession with agency in emancipatory political theory arrogantly misplaced because, in his eyes, history was not the servant of man. ${ }^{18}$ Imanishi did not object to Darwin's replacement of human agency by natural selection only to postulate an animal agency in the image of human agency instead. He rather paved the way for the holistic tradition of so-called interaction studies in Japanese primatology, which - to this day - assume an 'indecomposability of a social interaction into actions' (not to speak of distinct causal factors, which puts the approach at odds with natural-scientific perspectives on primate life). ${ }^{19}$

Considering that the British anthropologist Tim Ingold derived an almost identical ontology from reading the philosophical work of Gilles Deleuze and Félix Guattari, we might wonder how Japanese Japanese primatology really is (or how British British anthropology is, for that matter). ${ }^{20}$ The self-representation of the Kyoto school has certainly been shaped by a discourse of cultural uniqueness known as nihonjin-ron, which historians and anthropologists of science do not have to adopt. ${ }^{21}$ At all events, Ingold's insistence that 'flyer and kite should be understood not as interacting entities, alternately playing agent to the other as patient, but as trajectories of movement, responding to one another in counterpoint, alternately as melody and refrain', led him to say 'no' to all talk about agency. ${ }^{22}$ Of course, Euro-American post-humanities scholars have not reached consensus on the definition of animal agency and some might consider the assumption that action emerges from what is happening between entities to be compatible with their own relational understanding of the term. Moreover, nothing is per se wrong with applying one's emic concepts to the empirical material at hand. ${ }^{23}$ However, as an anthropologist attentive to differences between knowledge cultures, such discord about the concept of agency gives me pause and awakens my ethnographic curiosity. How do ape researchers - and their apes? - actually negotiate the latter's capacity for self-determination in the Pan-Homo cultures that have emerged around the Ai Project?

17 Imanishi, op. cit. (9), p. 75.

18 Christopher Goto-Jones, Political Philosophy in Japan: Nishida, the Kyoto School and Co-prosperity, London: Routledge, 2009, p. 3.

19 Nakamura, op. cit. (13), p. 146.

20 See also Osamu Sakura, 'Kinji Imanishi. A Japanese view of nature: the world of living things. Translated by Pamela J. Asquith, Heita Kawakatsu, Shusuke Yagi and Hiroyuki Takasaki', Primates 2005 (46), pp. 287289.

21 Margaret Sleeboom, Academic Nations in China and Japan: Framed by Concepts of Nature, Culture and the Universal, London: Routledge, 2004, pp. 47-49.

22 Tim Ingold, Being Alive: Essays on Movement, Knowledge and Description, New York: Routledge, 2011, p. 215.

23 Bruno Latour, Reassembling the Social: An Introduction to Actor-Network Theory, Oxford: Oxford University Press, 2005, p. 216; for disagreements within this camp see the attack on actor-network theory by Tim Ingold, 'When ANT meets SPIDER: social theory for arthropods', in Carl Knappett and and Lambros Malafouris (eds.), Material Agency, New York: Springer, 2008, pp. 209-215. 


\section{A Japanese synthesis}

Even though Tetsuro Matsuzawa is a Japanese primatologist, nothing of what the historical literature says about so-called Japanese primatology applies to his case automatically because he did not emerge from the Kyoto school lineage, neither socially nor intellectually. He trained as an experimental psychologist, not a fieldworker. How to get by in the wild he learned from climbing eight-thousanders as a passionate mountaineer. Only as the fourteenth president of the Academic Alpine Club of Kyoto he considered himself an heir to Imanishi, who had held this office from 1963 to 1967 and had written popular books about mountain climbing. Matsuzawa set himself apart from the Kyoto school by shifting the focus from the evolution of primate societies to that of our primate minds. In this endeavour, the most prominent points of reference have been American and European authors, ranging from Gustav Theodor Fechner and Noam Chomsky to David Premack and Jane Goodall.

Nevertheless Matsuzawa thought of his project as Japanese primatology because of what he described as its holistic or synthetic spirit: 'We don't like to segregate, we want to assemble things', he characterized the 'Japanese way of thinking'. ${ }^{24}$ Matsuzawa's assemblage of laboratory experiments and field observations created a space for chimpanzee research in the borderland between bench and field, which European and American biologists had carved out in the late nineteenth and early twentieth centuries. ${ }^{25}$ Whether we think of it as particularly Japanese or not, this synthesis put the town of Inuyama and the village of Bossou on the map of primatologists around the globe. That is not to say that Matsuzawa's hybridization of oriental and occidental primatology replaced the Kyoto school, which continues to be a strong force in the Japanese field - even though some of its representatives complain about their international marginalization. ${ }^{26}$ Yet the accumulation of disciplinary power within and beyond Japan in the hands of Matsuzawa - in 2016 the president of the International Primatological Society, general director of the Japan Monkey Centre, coordinator of the Primatology and Wildlife Science international graduate programme, and editor in chief of the world's oldest primatological journal Primates - suggests that the Ai Project changed the landscape and opened a genuinely new chapter in the history of Japanese primatology after Imanishi.

For a historian, it is relatively easy to reconstruct how Imanishi and his heirs related to the question of animal agency because, from Imanishi's friendship with Nishida and his comparison of his own evolutionist work with natural philosophy to today's colloquia, often bringing together Japanese primatologists and philosophers, the Kyoto school has actively engaged with philosophical thought. ${ }^{27}$ By contrast, although Matsuzawa was no foaming anti-metaphysician, he simply did not care enough about such speculations to work his way through the conceptual thicket of philosophical writings. Bored after

24 All quotes not accompanied by citations are taken from interviews, which the author conducted in 2015.

25 Robert E. Kohler, Landscapes and Labscapes: Exploring the Lab-Field Border in Biology, Chicago: The University of Chicago Press, 2002.

26 Nakamura, op. cit. (13).

27 Imanishi, op. cit. (10), p. 367. 
only a few pages, he had put aside Nishida's famous book An Inquiry into the Good, never to look at it again. ${ }^{28}$

And yet, although Matsuzawa used every opportunity to emphasize that he was no product of the Kyoto school of primatology, he considered the famous founder of the Kyoto school of philosophy his 'spiritual great-grandfather'. Kiyoko Murofushi, the head of the Section of Psychology at KUPRI, who had purchased Ai and who supervised the twenty-six-year-old assistant professor Matsuzawa's research with the chimpanzee infant, had trained under the psychologist Taro Sonohara, who in turn had been a student of Nishida's. Mediated by this academic lineage, Matsuzawa believed, he had inherited Nishida's holistic way of thinking - not, however, on an ontological but an epistemological level. Matsuzawa never theorized any fundamental indecomposability of social interactions but practised his own understanding of holism by synthesizing benchwork and fieldwork.

The resulting amalgamation of laboratory and field experiments as well as naturalistic observations of chimpanzee behaviour in the African forest and the Japanese laboratory generated a unique perspective on chimpanzee self-determination. Not as metaphysical freedom from determination tout court but as freedom from human determination - an issue affecting wild and captive animals differently. Recording responses to experimental stimuli in animals trained to perform certain tasks stands in a stark contrast to hands-off observations of the spontaneous behaviour of free-ranging animals. Yet even the laboratory research at KUPRI crucially depended on the chimpanzees' natural dispositions and - to use Matsuzawa's expression - their 'free will' to participate in experiments (which does not necessarily mean that their participation conformed to the researchers' study protocols). ${ }^{29}$ The chimpanzees at Matsuzawa's field site, on the other hand, lived in a human-dominated world around the village of Bossou confined by roads and fields. Matsuzawa's methodology integrated these contradictions, filling the gap between experimentation and naturalistic observation through hybrid practices such as field experiments in the wild as well as field observations and participant observation in the laboratory.

\section{A talking ape: 'Is there anything new?'}

In 1976 - a quarter-century after the Hayeses had taught their home-raised chimpanzee Viki to utter 'papa', 'mama' and 'cup', and a decade after the Gardners had begun to teach Washoe American Sign Language - Murofushi obtained a grant for the first and last Japanese ape language project. This money paid three assistant professors, Toshio Asano, Shozo Kohima and Tetsuro Matsuzawa, to explore the linguistic capacities of chimpanzees. ${ }^{30}$ When the research began, however, Asano and Kojima had left for

28 Kitaro Nishida, An Inquiry into the Good, New Haven, CT: Yale University Press, 1992.

29 Tetsuro Matsuzawa, 'Sociocognitive development in chimpanzees: a synthesis of laboratory work and fieldwork', in Tetsuro Matsuzawa, Masaki Tomonaga and Masayuki Tanaka (eds.), Cognitive Development in Chimpanzees, Tokyo: Springer, 2006, pp. 3-33, 20.

30 Keith J. Hayes and Catherine Hayes, 'The intellectual development of a home-raised chimpanzee', Proceedings of the American Philosophical Society (1951) 95, pp. 105-109; Allen R. Gardner and Beatrix T. Gardner (eds.), Teaching Sign Language to Chimpanzees, Albany: State University of New York Press, 1989. 
sabbaticals in the United States and it was up to the newly hired Matsuzawa to train and take care of $\mathrm{Ai}$ and two more chimpanzee infants, Akira and Mari. But his mind was set on a different question than whether apes could talk.

In the course of the 1980s, Ai had learned twenty-six Roman letters and twenty-five signs of an artificial language called Kyoto University Lexigram System (instead of Japanese kanji because the latter would have required too many pixels to be displayed on then available computer screens). This native of Guinea also used Arabic numerals to count up to six and to state how many objects of a particular kind and colour she saw. ${ }^{31}$ However, when Matsuzawa spent a sabbatical at the American psychologist David Premack's laboratory, the latter showed himself unimpressed by Ai's cosmopolitan language skills: 'The important point is that you taught the chimpanzee to do these things and the chimpanzee learned them', Matsuzawa remembered in an interview in 2015 his recently deceased mentor saying. 'Is there anything strange, anything new? I don't think so.' Premack must have felt that the young Japanese professor's first Nature publication could not teach him anything he had not yet known about chimpanzees because Matsuzawa had not given them the chance to be 'their own agents', as Premack and his co-workers would put it elsewhere. ${ }^{32}$ His critique aimed at what he took to be a behaviourist research design, which conditioned animals rather than affording them an opportunity to speak for themselves. In the language lessons of their chimpanzee Sarah, David and Ann Premack attended to whether her learning was confined to training examples, or if she could apply it to new cases. Unless a behaviour had fully undergone the transition that freed it of environmental control, they argued, it had not become a completely spontaneous act that the animal could exercise at her will, just like humans do. ${ }^{33}$

Whether apes could be taught to communicate in a human language, however, did not really concern Matsuzawa. As a reader of the German Estonian biologist Jakob von Uexküll and primed by research he had done as a student on stereoscopic vision in rats, a different question had caught his attention: 'How do chimpanzees perceive this world? Do they perceive it like we do?' The original Ai Project used ape language research as a means to address this question by way of psychophysics.

When Theodor Fechner coined the term 'psychophysics' in 1860, he described the object of this new field of study as the relationship between mind and matter, body and soul. While the natural sciences studied matter by way of outside observation, and psychology studied the mind through introspection, an understanding of their

31 Toshio Asano, Tetsuya Kojima, Tetsuro Matsuzawa, Kisou Kubota and Kiyoko Murofushi, 'Object and color naming in chimpanzees', Proceedings of the Japan Academy, Series B 58 (1982), pp. 118-122; Tetsuro Matsuzawa, 'Use of numbers by a chimpanzee', Nature (1985) 315, pp. 57-59; Matsuzawa, 'Form perception and visual acuity in a chimpanzee', Folia Primatologica (1990) 55, pp. 24-32.

32 David L. Oden, Roger K. Thompson and David Premack, 'Spontaneous transfer of matching by infant chimpanzees, Pan troglodytes', Journal of Experimental Psychology: Animal Behavior Processes (1988) 14, pp. 140-145, 144.

33 David Premack and Ann J. Premack, The Mind of an Ape, New York: W.W. Norton \& Company, 1983, p. 56. 
relationship had remained a matter of philosophical speculation. ${ }^{34}$ Fechner sought to capture this abstract object, not given to immediate experience, by developing mathematical formulae to describe how a physical stimulus and the resulting sensation, as experienced by a test subject, correlated with each other.

Human participants in psychophysics experiments usually became active when asked to express their sensations, either in words or in numbers. Using psychophysics to understand how other animals perceived the world, however, turned out to be a problem because they had no means to share their experience of a given stimulus with human researchers. At this point ape language research came in handy. If Matsuzawa could teach his chimpanzee subjects to use a language-like medium to communicate with him, they could provide access to their inner experience as they verbalized the kind of introspections that Fechnerian psychophysics required.

By the 1970s, American ape language research offered two alternative approaches. Viki's sorry abilities to talk to the Hayeses had taught primatologists that the chimpanzee vocal tract did not lend itself to speech. The Japanese psychologists also decided against teaching their chimpanzee infants American Sign Language because the gesturing between humans and apes offered ample opportunity for social cuing. To make ape language research more objective, Duane Rumbaugh and his wife Sue Savage-Rumbaugh had just introduced some of the first computer technology into the field. They trained their test subject Lana to match artificial symbols - so-called lexigrams - on a computer keyboard to various stimuli like objects or colours. As they presented these samples, Lana could not see the human experimenters and therefore could not receive any cues from them. A computer recorded her responses, unpolluted by the kind of human interpretation required to decipher a gesture. ${ }^{35}$ Thus the Rumbaughs implemented mechanical objectivity to reduce human interference in chimpanzee behaviour.

At the Primate Research Institute, Imanishi's disciple Masao Kawai, soon to become the institute's director, advocated an empathetic understanding of other primates, his socalled feel-one method or kyokan, which he claimed to be 'the most striking aspect of Japanese primate studies'. ${ }^{36}$ Anthropomorphic interpretations of animal behaviour bothered most Western primatologists at the time, but not their Japanese colleagues at least not those from the Kyoto school. Buddhist doctrine led the Japanese to believe that the same life flowed through humans and animals, argued Asquith - a point reiterated by Matsuzawa. ${ }^{37}$ But the neuroscientists and experimental psychologists at KUPRI were more closely aligned with the medical school in Tokyo than with the Kyoto school. Matsuzawa did not identify with either of these two camps dividing the institute. But in his experimental work he cherished objectivity more than empathy. Moreover, his more experienced co-worker Asano had previously used computers for his behaviourist

34 Gustav Theodor Fechner, Elements of Psychophysics (ed. Edwin Garrigues Boring and Davis H. Howes, trans. Helmut E. Adler), New York: Holt, Rinehart and Winston, 1966, p. 1.

35 Duane M. Rumbaugh (ed.), Language Learning by a Chimpanzee: The Lana Project, illustrated edn, New York: Academic Press, 1977.

36 Cited in Asquith, 'Some aspects of anthropomorphism', op. cit. (8), p. 318.

37 Asquith, 'Some aspects of anthropomorphism', op. cit. (8), p. 248. 
experiments with monkeys. So their group decided against the sign language approach and adapted Rumbaugh's paradigm to the Japanese ape language project.

The Ai Project's first goal was to understand how chimpanzees perceived and categorized colours. Matsuzawa and his colleagues started out with the behaviourist paradigm of discrimination learning. As the test subject sat on her own in a box roughly two metres by two metres, they showed her through a small window a stimulus such as different hues on Munsell colour chips, conforming with Japanese Industrial Standard. In response, the chimpanzee had to match this sample to the correct lexigram on the keyboard in front of her. If she got it right, a chime sounded and an automatic food dispenser provided a raisin or small piece of apple. If she failed to name the colour correctly, the machine played an unpleasant sound and the subject came away empty-handed. Thereby the chimpanzees learned to discriminate and name eleven colours. ${ }^{38}$

The behaviourist paradigm based such matching-to-sample tasks on an understanding of the organism as tabula rasa, which researchers could set with any associations they desired. By reinforcing the chimpanzees' use of a particular terminology to designate a given palette of colours while punishing deviations from this human-invented system of symbols, the Japanese experimenters sought to form the animals' behaviour in the image of their own species - or culture? Presumably, that was the reason why Premack felt that he had not learned anything new when Matsuzawa taught Ai how to apply Arabic numerals to quantities of objects just as he had taught her to name these objects' colours.

However, the chimpanzees were no putty in the experimenter's hands. When learning to name the eight different objects presented to them, it took Ai fifty-seven days while Akira needed ninety days and Mari struggled for 120 days. Matsuzawa related these very pronounced differences in learning rate to the chimpanzees' personalities: whereas Ai proved to be a patient student, the young male Akira often tried to solve cognitive problems by sheer force, hitting the computer and other experimental equipment as hard as he could. Mari, on the other hand, grimaced and screamed every time she failed in a trial. Looking back at his life's work in his last lecture series at Kyoto University in 2015, Matsuzawa explained with some regret that a teacher should adapt his teaching style to his students. In Mari's case, for example, errorless learning without the unpleasant sounds of the buzzer would have been more appropriate. 'But I was a rigorous scientist keeping to the same method', he said.

It was not just because the three chimpanzee infants did not fully comply with their behavioural engineering that it would be inappropriate to consider the human experimenters the only relevant actors. Unlike Asano, Matsuzawa was no behaviourist. 'I use the techniques, but I do not rely on the philosophy of Skinner', he maintained. 'I don't believe in the idea that every behaviour can be explained by operant conditioning. In that sense, I'm closer to ethology and fieldwork.' The most important part of the experiment only began once the Skinnerian conditioning was complete. It examined what Matsuzawa took to be a naturally occurring behaviour rather than an artefact of the

38 Asano et al., op. cit. (31). Tetsuro Matsuzawa, 'Colour naming and classification in a chimpanzee (Pan troglodytes)', Journal of Human Evolution (1985) 14, pp. 283-291. 
laboratory. Once the chimpanzees had learned to discriminate and name eleven standardized colours, he presented them with colour chips they had never seen before. 'Now my question was: how about this colour?' Matsuzawa explained this second step. 'You may say red, pink, orange, or brown. It's completely up to you. In contrast to discrimination tasks, there is no correct or incorrect answer.' The key question was not whether chimpanzees could use symbols to designate objects - the ape language projects had provided ample and uncontroversial evidence for that - but how the apes would generalize from what they had learned. Such stimulus generalization, as Skinner had called it in his book on language acquisition, was no direct product of conditioning but would be determined by innate features of the chimpanzee mind, Matsuzawa believed. ${ }^{39}$

From the chimpanzees' categorizations of new colours, Matsuzawa and his colleagues created a map, showing which hues the chimpanzees grouped together. They adopted this approach from the anthropologist Brent Berlin and the linguist Paul Kay's book Basic Color Terms, at the time Matsuzawa's bible. ${ }^{40}$ In opposition to the linguistic relativism of Edward Sapir's and Benjamin Whorf's earlier work, which had argued that differences between languages caused differences in their users' ways of seeing the world, Berlin and Kay's comparison of colour lexicons across languages arrived at a universalist conclusion: although differently developed, the colour terminologies of all human groups evolved towards one and the same categorization. ${ }^{41}$ Berlin and Kay speculated that species-specific biological structures were not only behind the universality of syntax, as postulated by Noam Chomsky, but could also be found in the realm of semantics. $^{42}$

The Chomskyan emphasis on deep cognitive structures generative of more contingent behaviours left a deep mark on Matsuzawa's thinking. This postulate of innateness contradicted both the linguistic relativity proposed by Sapir and Whorf and Skinner's assumption that animals acquired their behaviours by way of association learning. Combining the method of operant conditioning with a belief in the universality of the chimpanzee mind, the Ai Project had fallen into the tense space opened up by the late 1950s controversy between Skinner and Chomsky over whether mental faculties such as language developed as inborn human capacities or were gradually instilled by rewards and punishments. ${ }^{43}$ Matsuzawa explained, 'Many people think Ai is a genius. But for me $\mathrm{Ai}$ is a representative of chimpanzees, of all chimpanzees. I'm very much skewed toward species-specific universals.' However, although Matsuzawa stressed the innate over the conditioned, his adherence to Skinner's concept of stimulus

39 Burrhus Frederic Skinner, Verbal Behavior, Upper Saddle River: Prentice-Hall, Inc., 1957.

40 Brent Berlin and Paul Kay, Basic Color Terms: Their Universality and Evolution, Berkeley: University of California Press, 1969.

41 Edward Sapir, Language: An Introduction to the Study of Speech, New York: Harcourt, Brace and World, 1921. Benjamin Lee Whorf, Language, Thought, and Reality: Selected Writings of Benjamin Lee Whorf (ed. John B. Carroll), Cambridge, MA: MIT Press, 1956.

42 Berlin and Kay, op. cit. (40), p. 109. Noam Chomsky, Aspects of the Theory of Syntax, Cambridge, MA: MIT Press, 1965.

43 Skinner, op. cit. (39). Gregory Radick, 'The unmaking of a modern synthesis: Noam Chomsky, Charles Hockett, and the politics of behaviorism, 1955-1965', Isis (2016) 107, pp. 49-73. Noam Chomsky, 'A review of B.F. Skinner's Verbal Behavior', Language (1959) 35, pp. 26-58. 


\section{Nicolas Langlitz}

generalization prevented him from completely abandoning behaviourist thought and from climbing onto the bandwagon of the Chomskyan revolution.

Matsuzawa's cartography of the chimpanzees' colour space showed that it largely corresponded to the map which Berlin and Kay had proposed for humans. This finding confirmed earlier psychophysiological studies suggesting that the trichromatic colour perception of chimpanzees resembled our own. ${ }^{44}$ Although in accord with Chomsky's emphasis on inborn universals, Matsuzawa's account diverged from the structure of Chomsky's argument in that it provided evidence against species-specificity: 'These results suggest that there is a common basis of colour classification not only across human cultures but also across primate family lines, Hominidae and Pongidae.'45

Matsuzawa described the approach underlying this early work as the prototype of the Ai Project: a single subject conducting matching-to-sample or discrimination tasks in automated experiments - 'and they have to answer my questions'. Forcing the subject to choose among two or more sample stimuli and to match them to a so-called comparison stimulus, these discrimination tasks asked which stimuli corresponded to each other and they conditioned the animal to pick the right one. Only the subsequent stimulus generalization experiments provided opportunity for spontaneity on the chimpanzee's part. In Matsuzawa's eyes, it revealed the spontaneity of innate propensities - what ethologists used to call instincts - shared by the entire species. It did not indicate individual agency.

\section{Unsolicited behaviours: field observations in the laboratory}

The Ai Project exceeded a series of controlled experiments. It went along with forms of fieldwork, constantly situating experimental results in broader contexts. Around 1980, before tighter and tighter regulations precluded such carefree excursions, Matsuzawa took Ai for walks outside the institute. He brought coloured objects as well as the corresponding lexigram symbols and occasionally asked Ai to name the colour of some woodblock or spoon to see whether she generalized from her laboratory experience to situations of daily life. One day they sat in an orchard and, as Matsuzawa wrote down the results of such an informal test in his notebook, Ai picked a dandelion and handed him the lexigram for yellow. 'It was her who spontaneously used her vocabulary to describe the colours of her world to me', he remembered.

For several reasons, this and many episodes like it never made it into Matsuzawa's scientific articles. First, it lies in the nature of spontaneous behaviour that it occurs suddenly and without apparent external cause, which makes its methodical investigation difficult. But if reports were limited to opportunistically collected, singular events, scientific journals tended to dismiss them as anecdotal. Matsuzawa did publish these stories in his popular Japanese books, but felt that he was not fluent enough to write such monographs in English. Moreover, he wanted to set himself apart from American ape

44 W.F. Grether, 'Chimpanzee color vision I: hue discrimination at three spectral points', Journal of Comparative Psychology (1940) 29, pp. 167-177; A.H. Riesen, 'Chimpanzee visual perception', in Geoffrey H. Bourne (ed.), The Chimpanzee, vol. 2, Baltimore: University Park Press, 1970, pp. 93-119.

45 Matsuzawa, op. cit. (38), p. 290. 
language researchers who had put much weight on such episodes because demonstrating the ability of spontaneous language use was key to showing that chimpanzees were capable of linguistic communication, understood as a creative rather than conditioned combination and recombination of signs.

Such field observations were not confined to the outdoors. Matsuzawa also conducted them within the Primate Research Institute. Although his publications mostly presented experimental results proper, he systematically collected data on factors other than the displayed stimuli, which affected the chimpanzees' behaviour in the trial. 'I'm doing my fieldwork here in the laboratory', he explained. 'This is the chimpanzees' seminatural or artificial habitat.' The fully automated experiments allowed him to carefully observe and take notes on what the animals did in the laboratory setting while a computer system recorded their test performance. From the beginning of the Ai Project, film recordings provided these field observations in the laboratory with an objective basis. When I visited KUPRI in 2015, three video cameras captured every single trial from different angles, generating an enormous archive of contextual information that could be used to interpret the quantitative data from the tests.

One example of how such field observations offered additional insights comes from Matsuzawa's most famous experiment, demonstrating the cognitive superiority of a young chimpanzee over human subjects in a test of visual short-term memory. After learning to discriminate and order Arabic numerals from 1 to 9, a touchscreen presented chimpanzees with up to five numbers, which they had to tap in ascending order. In this so-called limited-hold memory task, the numbers only appeared for a blink of an eye - often a mere 210 milliseconds - before being masked by white squares. While human subjects regularly failed to memorize the numbers in their spatial distribution in such a short time, Ai's fiveyear old son Ayumu excelled at remembering them and outperformed all nine university students serving as controls. ${ }^{46}$ Located in the basement of KUPRI, Matsuzawa's laboratory rooms were not soundproof. As in the wild, where chimpanzees often forage out of sight of each other, the community, which had grown to fourteen individuals altogether, communicated through long-distance calls, so-called pant hoots, while participating in different experiments. On one occasion, Ayumu had begun tapping the masked numbers on the touchscreen in front of him when - unforeseen by the experimental protocol - some brouhaha in the group distracted him. As a young male he got passionate about chimpanzee politics (one of the reasons why researchers considered females to be better test subjects). For a moment - subsequent analysis of the video footage revealed that it was for exactly 10 seconds - he turned around and listened intently. Then he looked at the screen again and touched the remaining masked numbers in the right order. Matsuzawa concluded, 'It is very clear that there is a photographic memory in chimpanzees, which lasts for at least 10 seconds.'

The fact that this episode had been filmed and that other researchers who had not witnessed it themselves could look at it again and again, even though it only happened once, raised its epistemological value beyond that of mere anecdote. Matsuzawa gave Ayumu's

46 Sana Inoue and Tetsuro Matsuzawa, 'Working memory of numerals in chimpanzees', Current Biology (2007) 17, pp. R1004-R1005. 
shift of attention from procuring food by solving cognitive tasks to obtaining valuable information about the social dynamics of the group an ethological interpretation: as is typical of chimpanzees of his sex and age, he responded more strongly to external stimuli enabling him to work his way up the dominance-rank hierarchy.

By contrast, the last instance of a field observation in the laboratory I wish to present confirmed Matsuzawa's conviction that chimpanzees were no mere automatons, translating stimuli into responses, as both behaviourists and early ethologists had imagined animals. It occurred during my own fieldwork at the Primate Research Institute. When the chimpanzees came to the laboratory for thirty- to forty-five-minute sessions, different tasks awaited them. The researchers could not see the chimpanzee touchscreen, but the monitor of the laboratory computer mirrored the presentation of the stimuli. Every time an animal completed a task, a researcher went to this computer to enter new parameters for the next task. Until a few weeks before my arrival the chimpanzee screens blacked out during this time. But, when a doctoral student set up a new monitor system, she forgot to include the switch that decoupled the chimpanzees' screens from the humans' screen. Now, every time Ai and her conspecifics completed a task, they saw the Windows desktop with a dialog box appear. Well versed in her experiments, Matsuzawa's doctoral student always changed the parameters within seconds. But when she could not come to the laboratory one day, Matsuzawa adjusted the settings himself. Unfamiliar with this routine he was still double-checking his entries when Ai impatiently pressed the button with the Japanese kanji for 'Start' - and the experiment began. 'The first time, I thought it was by accident, but the next day she did it again', Matsuzawa recounted the incident a few weeks later. At that point, he always told Ai not to touch the screen before he was done. He had grown convinced that 'she has meta-knowledge of the system. She knows that, if she presses this button, the experiment starts. And she knows the right timing. She is waiting until I have entered all the necessary information.'

Kuklick and Kohler have pointed out that the uncontrollability of the field sets it apart from the laboratory. ${ }^{47}$ However, many historians and anthropologists of science, including myself, have shown that in reality even laboratories are not as controlled as the idealtypical conception of experiments carving out the effects of independent on dependent variables would require. ${ }^{48}$ 'You can often learn more about how chimpanzees think and see the world when experiments do not work out as planned', a field primatologist from Britain visiting Matsuzawa's lab told me. Although Matsuzawa's style of experimentation aimed at making the animals provide direct answers to confined questions, his view of the laboratory as field provided space for the observation of spontaneous behaviours that went beyond what the experimenter had asked.

47 Henrika Kuklick and Robert E. Kohler, 'Introduction to "Science in the Field”, Osiris (1996) 11, pp. 114,3 .

48 Nicolas Langlitz, Neuropsychedelia: The Revival of Hallucinogen Research since the Decade of the Brain, Berkeley: University of California Press, 2012. 


\section{Participation observation and the cultural correction device}

Since Bronislaw Malinowski's ethnographic approach of immersing himself in unfamiliar forms of human life had become paradigmatic in sociocultural anthropology, its practitioners have come to equate fieldwork with such participant observation. ${ }^{49}$ By 2015 , primatologists studying wild apes usually had come to make every effort not to participate in the social lives of their subjects, however - not only because any intervention potentially altered the observed behaviour but also because involving oneself in often violent chimpanzee politics could easily threaten a researcher's life and limb. In the 1960s, Jane Goodall had still experienced the magic moment of grooming her favourite chimpanzee David Greybeard. ${ }^{50}$ She paid the price for this intimacy with the Gombe community when David chased her through the jungle. Subsequent generations of primatologists largely shed field observation of participation. Instead they based it on habituation. Ideally, the animals became so accustomed to the presence of human observers that they behaved as if the at times strenuously disengaged researchers did not exist: 'In the field, we are like a breeze, like the air, like a rock', said Matsuzawa. 'The best situation is when the chimpanzees don't pay attention to me.' In contrast to laboratory experiments and participant observation, the goal of unmanipulated field observations is not to interact but to capture animal behaviour that has not been elicited by humans.

The Ai Project, however, departed from the North American ape language projects, which attempted to socialize non-human primates into human language use, sometimes by raising these hominoid infants like human children in human families. ${ }^{51}$ Even though Ai grew up in the laboratory, not his home, Matsuzawa engaged much more with her and the other chimpanzees at KUPRI than any primatologist, including himself, did with their research subjects in the field. It might be difficult to work with an orphaned one-year-old chimpanzee without being solicited as attachment figure and playmate. Direct interactions with young apes had also been common in American and European laboratories and zoo nurseries. The sociologist Lawrence Wieder studied face-to-face interaction between chimpanzees and chimpanzee researchers in the USA. ${ }^{52}$ Matsuzawa's approach differed from those of his Western colleagues - Sue Savage-Rumbaugh's study of adult bonobos aside - in that he and his co-workers continued to go in with their chimpanzees when they were fully grown and much stronger than any human. After Ai and two other females had given birth in the year 2000, the researchers continued to work in this fashion with the mother-infant pairs on a daily basis. They called this practice 'participant observation' or 'participation observation.'

49 Bronislaw Malinowski, Argonauts of the Western Pacific, London: Routledge, 1922.

50 Jane Goodall, In the Shadow of Man, New York: Houghton Mifflin Harcourt, 1971.

51 For example, Hayes and Hayes, op. cit. (30); Herbert S. Terrace, Nim: A Chimpanzee Who Learned Sign Language, London: Eyre Methuen, 1980; Roger Fouts, Next of Kin: What Chimpanzees Have Taught Me about Who We Are, New York: Morrow, William, \& Co., Inc., 1997. For an opinionated but thorough overview see Joel Wallman, Aping Language, Cambridge: Cambridge University Press, 1992; John Dupré, 'Conversations with apes: reflections on the scientific study of language', in Dupré, Humans and Other Animals, Oxford: Clarendon Press, 2002, pp. 236-257.

52 D. Lawrence Wieder, 'Behavioristic operationalism and the life-world: chimpanzees and chimpanzee researchers in face-to-face interaction', Sociological Inquiry (1980) 50, pp. 75-103. 
Participation observation grew out of a broader culture of mutual trust between humans and chimpanzees. It presupposed an intimate familiarity between researchers and apes. Knowledge and care became inseparable. Whereas most European and American laboratories maintained a strict division of labour between scientists and caretakers, at KUPRI doctoral students, postdocs and assistant professors regularly helped to feed the animals and to clean their cages. Matsuzawa considered daily feeding for at least six months an essential step towards building a relationship that would allow humans to safely enter into a room with a chimpanzee.

The direct interactions enabled by Pan and Homo sharing a space with each other made possible a whole range of new practices. Ai and even Akira, by now the group's alpha male, allowed Matsuzawa to stick needles into their arms, patiently watching as he injected them with vaccines or anaesthetics. No handling cage restrained the animals. When the young chimpanzee mothers had difficulties taking care of their newborns, as so many human-reared apes do, they let human intimates show them how to hold and nurse a baby. Caring for chimpanzees in these ways generated forms of understanding that could not be gained from experiments. Naruki Morimura, an associate professor who had adopted the approach of participant observation at Kumamoto Sanctuary, an institution Matsuzawa described as KUPRI's 'spiritual twin', explained how direct interactions provided a most immediate mechanism to falsify the researchers' hypotheses about chimpanzee behaviour in daily life, with no need for experimental controls or statistical analyses: 'If we misunderstand the chimpanzees, we will be in trouble. It's a very serious situation. We try to enjoy playing with them. But, if we fail reading their minds, they might attack us.' From the point of view of a behaviourist experimenter, interpreting an animal's intentions might be pure speculation. Consequently, no 'thick description' could reveal the meaning of what a chimpanzee did. ${ }^{53}$ But in participation observation it is the chimpanzees who will clear things up in their own potentially violent ways should a misunderstanding occur. In an account of her work with bonobos, Sue SavageRumbaugh referred to this as the 'cultural correction device' of Pan-Homo ethnography. ${ }^{54}$

Unhindered physical contact with the chimpanzees also enabled the application of measurement technologies, which required a direct and trustful management of behaviour not possible through wire mesh and Plexiglas walls. Ultrasound exams of pregnant females provided novel insights into foetal development. ${ }^{55}$ Researchers could mount eyetracking goggles on a chimpanzee's head to follow his gaze under naturalistic conditions,

53 Clifford Geertz, 'Thick description: toward an interpretive theory of culture', in Geertz, The Interpretation of Cultures: Selected Essays, New York: Basic Books, 1973, pp. 3-30.

54 Sue Savage-Rumbaugh, William M. Fields, Pär Segerdahl and Duane Rumbaugh, 'Culture prefigures cognition in Pan/Homo bonobos', Theoria: Revista de Teoría, Historia Y Fundamentos de La Ciencia (2005) 20, pp. 311-328, 313.

55 Tomoko Sakai, Satoshi Hirata, Kohki Fuwa, Keiko Sugama, Kiyo Kusonoki, Haruyuki Makishima, Tatsuya Eguchi, Shigehito Yamada, Naomichi Ogihara and Hideko Takeshita, 'Fetal brain development in chimpanzees versus humans', Current Biology (2012) 22, pp. R791-R792; Hideko Takeshita, Masako Myowa-Yamakoshi and Satoshi Hirata, 'A new comparative perspective on prenatal motor behaviors: preliminary research with four-dimensional ultrasonography', in Tetsuro Matsuzawa, Masaki Tomonaga and Masayuki Tanaka (eds.), Cognitive Development in Chimpanzees, Tokyo: Springer, 2006, pp. 37-47. 
shedding light on social cognition. ${ }^{56}$ Electrocardiography produced more continuous recordings of heart activity if a researcher could be with a chimpanzee and keep him still than if electrodes had to be stuck through the bars of a cage. Moreover, the neural processes underlying chimpanzee thought could be recorded in a fully awake individual, which allowed a researcher to attach EEG electrodes to her head and to prevent the ape from moving around during the measurement. ${ }^{57}$ None of these instrumental recordings would have been feasible without the animals' active involvement.

However, in Matsuzawa's more narrow definition, the term 'participant observation' was reserved for studies of the sociocognitive development not, as in many ape language projects, of isolated subjects, but of mother-infant pairs living in a grown multigenerational community of chimpanzees. ${ }^{58}$ Developmental psychology provided most paradigms to test object manipulation, tool use, drawing skills, face recognition, imitation or the cultural transmission of knowledge and skills from one generation to the next. The bond between the participating mothers and the researchers allowed conducting the experiments under the same conditions as in human laboratories: in a face-to-face situation, in the presence of the mother, and with what Matsuzawa described as her 'cooperation'.59 By evading critiques of unfair differences in experimental conditions privileging our species, this approximation of human and chimpanzee testing provided validity to cross-species comparisons. ${ }^{60}$

Since the end of the ape language projects, mostly Japanese laboratories have employed the kind of direct interactions described in this section. Satoshi Hirata and Naruki Morimura took their mentor Matsuzawa's approach one step further and pioneered participant observation in a whole group of chimpanzees. Yet Hirata rejected a culturalist interpretation of the practice. In the past, many European and American researchers had also interacted directly with their apes, he pointed out in an interview: 'Faced with chimpanzees, we independently developed a similar style based on close relations and friendship.' Both in Japan and in the West, there was no shortage of counterexamples where neither amity nor participant observation grew out of the encounter between Pan and Homo. But where the bonds of mutual trust did emerge, it seems as if chimpanzees had contributed as much as humans. 'The chimpanzees also domesticated the humans', concluded Akira Takada from his behavioural analysis of interactions

56 Fumihiro Kano, Masaki Tomonaga and Eric James Warrant, 'Head-mounted eye tracking of a chimpanzee under naturalistic conditions', PLoS ONE (2013) 8, p. e59785.

57 Ari Ueno, Satoshi Hirata, Kohki Fuwa, Keiko Sugama, Kiyo Kusonoki, Goh Matsuda, Hirokata Fukushima, Kazuo Hiraki, Masaki Tomonaga and Toshikazu Hasegawa, 'Brain activity in an awake chimpanzee in response to the sound of her own name', Biology Letters (2010) 6, pp. 311-313; Ari Ueno, Satoshi Hirata, Kohki Fuwa, Keiko Sugama, Kiyo Kusonoki, Goh Matsuda, Hirokata Fukushima, Kazuo Hiraki, Masaki Tomonaga and Toshikazu Hasegawa, 'Auditory ERPs to stimulus deviance in an awake chimpanzee, Pan troglodytes, towards hominid cognitive neurosciences', PloS One (2008) 3, p. e1442.

58 Matsuzawa, op. cit. (1); Matsuzawa, op. cit. (29).

59 Matsuzawa, op. cit. (1), p. 208.

60 Christophe Boesch, 'What makes us human (Homo sapiens)? The challenge of cognitive cross-species comparison', Journal of Comparative Psychology (2007) 121, pp. 227-240; Boesch, 'Taking development and ecology seriously when comparing cognition: reply to Tomasello and Call, 2008', Journal of Comparative Psychology (2008) 122, pp. 453-455. 


\section{Nicolas Langlitz}

between the team around Hirata and Morimura and their captive apes. ${ }^{61}$ The chimpanzees' nature and ability to learn socially from each other and from us shaped the resulting research practices as much as any human culture. But note that Takada's approach followed the paradigm of Japanese interaction studies in that it 'did not disconnect the sender and the receiver of information in the actual interactions, but used the relationship between them as the unit of analysis'. ${ }^{62}$ You can only read agency into Takada's analysis if you dismiss Ingold's objections to the term.

\section{Free animals and experimental control in an outdoor laboratory}

When Matsuzawa first visited Ai's wild relatives in Bossou, Guinea, in 1986, participant observation was out of the question. First he came for one month every winter to observe without intervening at all in the chimpanzee community's life. Yukimaru Sugiyama, the Kyoto school primatologist who had initiated the long-term research project at Bossou in 1976, cherished this purist approach. As Sugiyama took over more administrative functions in Kyoto from 1990 onward, he asked Matsuzawa to direct the field station in his stead. In the early twentieth century, careers in the borderland between field and laboratory were supposed to progress from the former to the latter. ${ }^{63}$ By contrast, Matsuzawa decided to go beyond benchwork only after he had already established himself as an experimental psychologist. As such, however, he had not trained to conduct naturalistic observations. And, taking care of a laboratory in Inuyama, he was too busy to patiently collect behavioural data at the chimpanzees' pace. For him, field observations accrued as a mere by-product of the outdoor laboratory he had established in 1988. Making a virtue of necessity, he built a highly productive research apparatus for field experiments that quickly made him 'the foremost practitioner' of such quasi-experiments in nature, as his British colleague William McGrew attested. ${ }^{64}$

In primatology, the history of field experiments dates back to the 1890s, when Richard Garner took a phonograph to New York's Central Park, recording and playing back calls of monkeys and apes to test their reactions - an experiment he planned to repeat in the Congolese jungle. ${ }^{65}$ Before Sugiyama's arrival, the Dutch researcher Adriaan Kortlandt had brought the ethological tradition of combining fieldwork and experiment to Bossou, where he had presented the chimpanzees with an electric-powered stuffed leopard that could shake its head. ${ }^{66}$ Such interventions had also been part of Japanese primatology from the start. Not only was food provisioning considered one of its

61 Akira Takada, 'Mutual coordination of behaviors in human-chimpanzee interactions: a case study in a laboratory setting', Revue de primatologie (2013) 5, pp. 1-21, 16.

62 Takada, op. cit. (61), p. 17.

63 Kohler, op. cit. (25), p. 174.

64 William C. McGrew, The Cultured Chimpanzee: Reflections on Cultural Primatology, Cambridge: Cambridge University Press, 2004, p. 45.

65 Gregory Radick, The Simian Tongue: The Long Debate about Animal Language, Chicago: The University of Chicago Press, 2007.

66 Gen Yamakoshi, "The "prehistory” before 1976: looking back on three decades of research on Bossou chimpanzees', in Tetsuro Matsuzawa, Tatyana Humle and Yukimaru Sugiyama (eds.), The Chimpanzees of Bossou and Nimba, Tokyo: Springer Japan, 2011, pp. 35-44, 37-40. 
hallmarks, but Imanishi's student Masao Kawai had also conducted field experiments on the macaques of the island of Koshima since the 1950s. ${ }^{67}$ Thus Matsuzawa's approach built on both Japanese and Euro-American antecedents.

Sugiyama, however, opposed such human interference. He criticized both his Kyoto school colleagues and Jane Goodall for feeding the animals they observed. At Bossou, he wanted to keep the chimpanzees' behaviour as natural as possible. As outgoing director of the field site, he frowned on the introduction of field experiments. In an interview I conducted in 2015, his student Osamu Sakura, now a science studies scholar at Tokyo University, pointed to the contradictory nature of Sugiyama's position:

I was quite surprised when I first saw Bossou. The chimpanzees lived just behind the village, which was home to 2,000 people. Yes, they were wild, but their environment was quite artificial. It was true that the researchers did not feed them, but the chimpanzees always ate humancultivated crops and stole pineapples. So I was really confused about what was natural.

Researchers working with great apes tended to shy away from field experiments, worrying that their interventions might lead to unwanted long-term effects. ${ }^{68}$ And if they conducted a field experiment, they usually considered not altering the animals' habitat an important precondition. Yet Sakura had no ethical qualms when he helped Matsuzawa in 1988 not just to reintroduce ad hoc experiments but also to establish a seasonal outdoor laboratory, providing oil palm nuts to investigate how the chimpanzees opened them with stone tools. 'In Bossou, humans are providing nuts everywhere', Matsuzawa justified their intervention in the apes' anthropogenic feeding ecology. With or without their field experiments, Bossou was anything but a pristine habitat.

Also known as Le Bureau, the Japanese laboratory in a former French colony was located in the woods right next to a fig tree, which the chimpanzees frequently visited. Going to 'the office' instead of conducting field observations in the dense secondary forest surrounding Bossou had a whole range of advantages. First, researchers and field assistants sat comfortably on slightly hidden chairs approximately fifteen metres from the animals with no foliage obstructing the view. The artificial setting gave them many more opportunities than the forest to systematically observe even rare behaviours, generating more data in less time. For example, in the past three decades, during almost thirty months in the field, Matsuzawa witnessed three times how chimpanzees used leaf sponges to drink water from tree holes. Drilling an artificial hole into a tree trunk in the laboratory, which an assistant regularly filled with water, multiplied opportunities for observation: 'Now you can see the behaviour every day, any time you want.'

Second, colleagues who had never seen the animals in the field could carefully examine each instance of the behaviour by watching its video recording again and again, even in slow motion. As in the indoor laboratory, at least two camcorders recorded the chimpanzees' every move from different angles. Matsuzawa had introduced such video cameras in 1987, shortly after Sony had commercialized the first battery-powered models in

67 Masao Kawai, 'On the rank system in a natural group of Japanese monkey (I) - the basic and dependent rank’, Primates (1957) 1, pp. 111-130.

68 Klaus Zuberbühler, 'Experimental field studies with non-human primates', Current Opinion in Neurobiology (2014) 28, pp. 150-156. 
Japan. Thus Matsuzawa carried the long-standing tradition of mechanical objectivity in animal behaviour studies into the age of consumer electronics - a tradition which Gregg Mitman has traced back all the way to Etienne-Jules Marey's analysis of animal motion with the help of a chronophotographic gun in 1882 and Ray Carpenter's $16 \mathrm{~mm}$ film recordings of social behaviour of rhesus monkeys in the 1930s. ${ }^{69}$ Providing an analogue to the replicability expected of controlled laboratory experiments, the resulting footage enabled fieldworkers to go beyond anecdotal evidence. Shared at scientific meetings, it helped to convince others of the researchers' observations and theoretical claims. Moreover, collected over thirty years, the resulting video archive enabled long-term analyses of chimpanzee traditions - a cultural history of the Bossou community, if you will.

Le Bureau also provided the researchers with a higher level of control over the chimpanzees' environment than naturalistic observations. For example, they quantified the amounts of water extracted from the hole. They knew how much the available stone hammers weighed, which different animals used for cracking nuts. They could even manipulate the tools or test how the chimpanzees dealt with unfamiliar kinds of nuts. ${ }^{70}$

The outdoor laboratory also allowed studying how chimpanzees responded to a particular stimulus in a more natural situation. For instance, Sakura noted that laboratory experiments usually isolated test subjects: 'But in the field, they form their natural social groups. If the dominant animal wants to use this stone, the other animals have to wait till the dominant one finishes. So we can observe a lot of the social parameters.' In light of the sociological opposition of individual agency and social structures, such spontaneous deference could hardly count as an example of chimpanzee agency, but, in comparison to the indoor laboratory, field experiments did reduce human impact, giving more room to what the animals did on their own initiative.

The historian of science Gregory Radick contrasted the lab-based ape language projects, 'which had bent the wills of the animals to the experimenters' interests', to field experiments that 'had let the animals be free': instead of teaching them in the scientists' world, the scientists 'had taken themselves to the animals' world in order to learn'. ${ }^{71}$ This combination of relatively natural life and relative experimental control led Radick to claim that 'the conducting of a field experiment brought with it an unbeatable combination of moral and epistemic authority: the authority of experiment over observation or speculation, and the authority of nature over artifice'. ${ }^{72}$ In his career, Matsuzawa banked on the epistemic power of such hybridization:

My research approach has focused on synthesizing these two different approaches (observation and experiment) and these two different study environments (natural habitat and laboratory

69 Lorraine Daston and Peter Galison, Objectivity, New York: Zone Books, 2007; Gregg Mitman, 'Cinematic nature: Hollywood technology, popular culture, and the American Museum of Natural History', Isis (1993) 84, pp. 637-661; Georgina M. Montgomery, 'Place, practice and primatology: Clarence Ray Carpenter, primate communication and the development of field methodology, 1931-1945', Journal of the History of Biology (2005) 38, pp. 495-533.

70 Tetsuro Matsuzawa, 'Field experiments of tool-use', in Matsuzawa, Humle and Sugiyama, op. cit. (66), p. 160.

71 Radick, op. cit. (65), p. 364.

72 Radick, op. cit. (65), p. 368. 
setting). I thus developed two paradigms: (1) field experiments in the wild and (2) participation observation in the laboratory. In my view, this holistic approach is the most suited in providing us with a truer and deeper understanding of chimpanzees as a whole. ${ }^{73}$

In a conversation about the underlying philosophy, Matsuzawa attributed a Hegelian spirit to his methodology: 'When I spoke of synthesis I thought of dialectics: thesis, antithesis, synthesis. For me, the thesis is laboratory work, the antithesis is fieldwork, and the synthesis is my work.' This does not mean, however, that field experiments or participant observation in the laboratory represented the ultimate approach. They did not result in a Hegelian form of Aufhebung that simultaneously abolished, preserved and transcended thesis and antithesis. If primatologists could have the experimental cake and eat it naturally, they could abandon all other approaches.

But field experiments always compromise and come with their own disadvantages. As Matsuzawa's collaborator McGrew remarked about Bossou, 'Their “outdoor laboratory" is limited by natural constraints: trials cannot be scheduled nor subjects assigned randomly to treatment. ${ }^{74}$ Although researchers could manage confounding variables better than in the forest, they handled control conditions less stringently than in their indoor facility. If they investigated what physical qualities chimpanzees looked for in a good stone hammer while the dominance-rank hierarchy of the group constrained their subjects' selection, a more human-controlled situation excluding dominant individuals could provide less noisy data by giving subordinate individuals more freedom to pick their hammer of choice. In this case, an indoor lab would produce better data. If, on the other hand, researchers studied how much of their caloric intake chimpanzees met by eating nuts during the nut-cracking season, then human provisioning of those nuts in the outdoor lab was bound to distort the results. Consequently, naturalistic observation would produce superior data. When the psychologist Ray Carpenter laid the foundations for the methodological toolkit of modern primatological fieldwork, he saw its main advantage in providing access to natural behaviour - an advantage that human interventions would gamble away. Following his plea for keeping laboratory and field distinct to preserve their respective strengths, the historian of primatology Georgina Montgomery has questioned the epistemological wisdom of Radick's celebration of the field experiment as an amalgamation of naturalistic observation and experimental manipulation. ${ }^{75}$ Matsuzawa, however, did not replace a pluralist methodology with a single hybrid approach, but regarded field experiments as a mere bridge between field observations and laboratory experiments. They did not sublate but complement and connect classical field- and benchwork. Matsuzawa explained that field experiments helped 'improve the ecological and social validity of cognitive experiments in the laboratory. This kind of inverse translational approach gave us the idea of "participation observation", which relies on the daily-life, direct face-to-face observation of captive chimpanzees. ${ }^{76}$ In other words, he forged a whole chain of translations between

73 Matsuzawa, op. cit. (70), p. 157.

74 McGrew, op. cit. (64), p. 182.

75 Montgomery, op. cit. (69).

76 Matsuzawa, op. cit. (70), p. 163. 


\section{Nicolas Langlitz}

rigidly controlled experiments, field observations and participant observation in the indoor laboratory, field experiments in the outdoor laboratory, and field observations in the forest. Even less controlled than research in Le Bureau, the latter promised to grant the apes a maximum of freedom from human meddling.

\section{Self-determination or adaptation to an anthropogenic world? Ethnoprimatological field observations}

Field observations of wild chimpanzees require much patience. Fieldworkers subject themselves to the mercy of their subjects' whims. They depend as much on environmental contingencies as the animals they follow. They only get to witness rare behaviours at the frequency of their natural occurrence. A good example is a recent study on palmwine consumption among the Bossou chimpanzees - from Matsuzawa's perspective one of the by-products of his team's work in the outdoor laboratory. It took a collective of researchers seventeen years to record twenty drinking sessions. ${ }^{77}$ This study also indicates that, since Sugiyama's departure, no one had even imagined fieldwork at Bossou to take place in pristine nature any more. The chimpanzees shared their territory with the villagers and frequently raided their crops as well as the plastic containers which people set up to collect the fermented sap of raffia palms. Naturalistic observations of tipsy or road-crossing chimpanzees at Bossou have contributed to the budding field of ethnoprimatology, which aspires to integrate primatology and sociocultural anthropology for the purpose of studying the lives and interactions of non-human with human primates in anthropogenic environments. ${ }^{78}$ Hence, in a generous reading, the ethnoprimatological module would even assimilate ethnography and ethnology into Matsuzawa's synthetic primatology. But, as the French ethnologist Vincent Leblan points out, 'ethnoprimatology is less governed by anthropological issues than by adaptive approaches to biological conservation'. 79

Agustín Fuentes, one of the pre-eminent scholars in this field and probably the one most conversant with contemporary cultural anthropology, described the object of ethnoprimatology as the 'multispecies interface ... in which the two species are simultaneously actors and participants in sharing and shaping mutual ecologies' ${ }^{80}$ Taking his cues both from niche construction theory in evolutionary biology and from the animal studies literature in the humanities, which postulates animal agency, Fuentes suggested that the 'traditional language of evolutionary adaptation' failed to elucidate how other primates not only passively adjusted to an environment that humans had

77 Kimberley J. Hockings, Nicola Bryson-Morrison, Susana Carvalho, Michiko Fujisawa, Tatyana Humle, William C. McGrew, Miho Nakamura, Gaku Ohashi, Yumi Yamanashi, Gen Yamakoshi and Tetsuro Matsuzawa, 'Tools to tipple: ethanol ingestion by wild chimpanzees using leaf-sponges', Royal Society Open Science (2015) 2, pp. 1-6.

78 Agustín Fuentes and Kimberley J. Hockings, 'The ethnoprimatological approach in primatology', American Journal of Primatology (2010) 72, pp. 841-847.

79 Vincent Leblan, 'Introduction: emerging approaches in the anthropology/primatology borderland', Revue de primatologie (2013) 5, pp. 1-16, 3.

80 Agustín Fuentes, 'Naturalcultural encounters in Bali: monkeys, temples, tourists, and ethnoprimatology', Cultural Anthropology (2010) 25, pp. 600-624, 600. 
created but also actively contributed to creating the ecological niche in which they coexisted with Homo sapiens. ${ }^{81}$ Although Fuentes's own account had grown out of European and American scholarship, he noted that the perception that organisms assimilated their environment through their bodies and that their bodies 'environmentalized' their local ecologies converged with Kinji Imanishi's critique of the classical Darwinian paradigm of natural selection, in which organisms either adapted or perished. ${ }^{82}$

Even in a largely agricultural environment like Bossou, chimpanzees shaped the habitat they shared with humans, as Imanishi and Fuentes claimed. Kimberley Hockings, a British ethnoprimatologist who did her doctoral research at Matsuzawa's field station, gave an example: chimpanzees fed on and dispersed cacao seeds across their home range. But the cacao plants failed to reach maturity within the forest and only produced fruit when deposited by chimpanzees in human farms where humans took care of the saplings by restricting weed growth and providing the right amount of shade. ${ }^{83}$ Overall, however, this Pan-Homo co-construction of an ecological niche was highly asymmetrical. In their ability to remake environments for their own purposes modern humans overtrumped all other ape species by far.

Independent of the impact of chimpanzee behaviour, primatological and ethnoprimatological field observations revealed what chimpanzees did spontaneously in a world where they had infinitely more possibilities than in captivity. Of course, their decisions were shaped by the affordances and pressures of an anthropogenic environment. ${ }^{84}$ But, in the face of these constraints, each individual made her own choices. For example, half of the Bossou chimpanzees had never been seen to drink alcohol. Such field observations were the least-controlled form of knowledge production in primatology. They left open why certain individuals abstained, whether the chimpanzees drank the palm sap because of alcohol or sugar content, etc. But like no other approach they brought to light the full, if relative, extent of the animals' self-determination in the wild. Relative because their spaces of possibilities had always been opened up and delimited by local environments. In recent history, human culture had profoundly transformed these environments and rapidly eroded chimpanzee livelihoods. Animal agency or not, there was next to nothing apes could do about us.

81 Fuentes, op. cit. (80), p. 610.

82 Fuentes, op. cit. (80), p. 603; Imanishi, op. cit. (9), pp. 74-78.

83 Kimberley J. Hockings, Gen Yamakoshi and Tetsuro Matsuzawa, 'Dispersal of a human-cultivated crop by wild chimpanzees (Pan troglodytes verus) in a forest-farm matrix', International Journal of Primatology, 2 November 2016, pp. 1-22.

84 Kimberley J. Hockings, Matthew R. McLennan, Susana Carvalho, Marc Ancrenaz, René Bobe, Richard W. Byrne, Robin I.N. Dunbar, Tetsuro Matsuzawa, William C. McGrew, Elizabeth A. Williamson, Michael L. Wilson, Bernard Wood, Richard W. Wrangham and Catherine M. Hill 'Apes in the Anthropocene: flexibility and survival', Trends in Ecology \& Evolution (2015) 30, pp. 215-222. 


\section{Nicolas Langlitz}

\section{Conclusion}

'There is no distinction between active and passive in reality, for they are the two sides of one reality', wrote Kitaro Nishida. ${ }^{85}$ So indebted to Nishida's philosophy that he copied whole passages of the philosopher's An Inquiry into the Good into his own book The World of Living Things, Imanishi refused to divide the world into agents and patients, imagining that the environment made those organisms live that chose to live as they reacted to the environment by eating food, avoiding enemies and seeking mates. ${ }^{86}$ This belief in a 'nondetermination within determination' fuelled Imanishi's reservations about the notion of natural selection, which only admitted the influence of the environment on the organism, but not the latter's response. ${ }^{87}$

And yet Imanishi concluded his essay with a surprising qualification: Darwinian natural selection did occur in one particular set of occasions. As Europeans had invaded ecologically isolated regions such as Australia, bringing with them other, more advanced, mammals, they had often driven the native fauna extinct. ${ }^{88}$ The influx of invasive species, spearheaded by modern humans, disrupted the peaceful equilibrium and established hierarchies of any affected species society, depriving its members of the freedom to choose life over death through their interactions with an environment now eliminating them one by one. Ironically, Imanishi deemed only anthropogenic environments capable of so-called natural selection.

Since primatological observation began in Bossou in the 1960s, the human population of the village had grown from a thousand to over four thousand inhabitants, while the number of chimpanzees had dropped from twenty-two to eight. When I visited Matsuzawa's outdoor laboratory in late 2015, he augured that we would be the last to see the Bossou chimpanzees. If we understood Margo DeMello's claim that laboratory animals 'have no agency, no ability to control their own lives' as implying that, conversely, wild animals would exercise such control over their lives, the helplessness of the Bossou community in the face of their imminent extinction would suggest otherwise. ${ }^{89}$

On the other hand, my account of Matsuzawa's laboratory research above also indicates that, even in captivity, Ai and her conspecifics made choices and behaved in ways unforeseen by the researchers. In 2015, Matsuzawa built the fully automated Sky Lab with experimental walk-in booths that the chimpanzees could access and leave as they pleased, at any time of the day. Face recognition software would identify each individual, a computer would present the next scheduled test, and an automated food dispenser would provide rewards as an incentive for the chimpanzees to participate in the research at their own discretion.

Neither this nor any other of the historical, ethnographic and primatological material presented in this article allows ruling out causal determinations of chimpanzee behaviour. However, many of the stories, observations and experiments I have discussed do

85 Nishida, op. cit. (28), p. 65.

86 Asquith, op. cit. (9), p. 35.

87 Imanishi, op. cit. (9), p. 74.

88 Imanishi, op. cit. (9), p. 86.

89 Margo DeMello, Animals and Society: An Introduction to Human-Animal Studies, New York: Columbia University Press, 2012, p. 50. 
suggest that human impact on what the chimpanzees did varied significantly between research sites and practices. Matsuzawa and his colleagues worked and continue to work deliberately with these variations, both in the laboratory and in the field. They have learned from the straight answers to straight questions that controlled experiments provide (at least according to methodology textbooks). They have also learned from observations of their test subjects' ingenious transgressions of experimental protocol and the spontaneous behaviour of free-ranging apes. The synthesis of these approaches had become the hallmark of the Ai Project.

Having reached the Japanese retirement age in 2016, Matsuzawa passed the laboratory on to his successor Masaki Tomonaga and vowed to use the freedom he had thus gained to meet his obligations, upholding his care for Akira, Mari and Ai until the end of their lives. His principal subject and research partner continued to volunteer in captive studies in an artificial environment that had made this peculiar representative of all chimpanzees live past her fortieth birthday. She continued to engage with the small artificial world that had become her home both actively and patiently. Such were Nishida's two sides of one reality. But maybe there are more than just two? 